\title{
Current pulse based ion-selective electrodes for chronopotentiometric determination of calcium in seawater
}

\author{
Shuwen Liu ${ }^{\text {a, c }}$, Jiawang Ding a, b, *, Wei Qin ${ }^{\text {a, b }}$ \\ ${ }^{a}$ Key Laboratory of Coastal Environmental Processes and Ecological Remediation, Yantai Institute of Coastal Zone Research (YIC), Chinese Academy of \\ Sciences (CAS), Shandong Provincial Key Laboratory of Coastal Environmental Processes, YICCAS, Yantai, Shandong, 264003, PR China \\ ${ }^{\mathrm{b}}$ Laboratory for Marine Biology and Biotechnology, Qingdao National Laboratory for Marine Science and Technology, Qingdao, 266237, PR China \\ ' University of the Chinese Academy of Sciences, Beijing, 100049, PR China
}

\section{H I G H L I G H T S}

- A current pulse based ion-selective electrode with enhanced sensitivity is proposed.

- The super-Nerstian responses of the electrode could be modulated by current pulse.

- The current pulse based Ca-ISE was successfully used for seawater analysis.
G R A P H I C A L A B S T R A C T

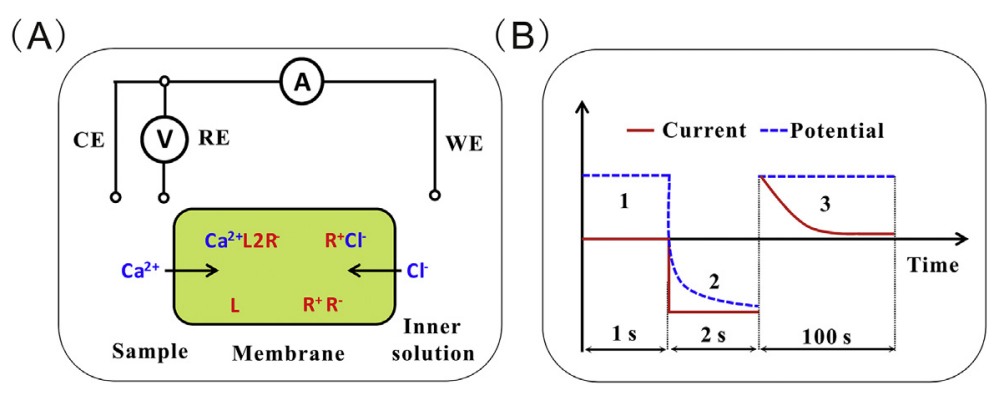

\begin{abstract}
A B S T R A C T
Calcium is closely related to the oceanic biosphere and carbonate system. Potentiometry based on a calcium-selective electrode (Ca-ISE) represents a promising tool for detection of calcium ion activities in seawater. This technique, however, generally is limited by the low sensitivity for the inherent Nernstian response (i.e. ca $30 \mathrm{mV} / \mathrm{dec}$ ). A current pulse based ion-selective electrode with enhanced sensitivity for chronopotentiometric measurements of calcium in seawater is proposed. The $\mathrm{Ca}^{2+}$-selective membrane containing lipophilic salt ETH 500 instead of traditional ion-exchanger is galvanostatically controlled. An applied constant cathodic current pulse can leads to the extraction of the calcium ions into the membrane to produce a chronopotential response, which shows a stable and reproducible super-Nernstian response in a narrow calcium activity range. The super-Nernstian region of the electrode depends on not only the the magnitude and duration of the applied current pulse but also the interfering ions. Under optimal conditions, the proposed Ca-ISE exhibits a super-Nernstian response between the calcium concentrations of $10^{-2.5}-10^{-1.5} \mathrm{M}$ with a slope of ca $80 \mathrm{mV} / \mathrm{dec}$. The current pulse based Ca-ISE has been applied to determination of calcium in seawater with satisfactory results.
\end{abstract}

(C) 2018 Published by Elsevier B.V.

\footnotetext{
* Corresponding author. Key Laboratory of Coastal Environmental Processes and Ecological Remediation, Yantai Institute of Coastal Zone Research (YIC), Chinese Academy of Sciences (CAS), Shandong Provincial Key Laboratory of Coastal Environmental Processes, YICCAS, Yantai, Shandong, 264003, PR China.

E-mail address: jwding@yic.ac.cn (J. Ding).
}

\section{Introduction}

Calcium, one of the major cations in seawater, is closely related to oceanic biosphere and carbonate system. It is the essential nutrient element in the growth of marine organism [1,2], especially in the formation of skeletons and shells [3]. In the context of the 
oceanic carbonate system, calcium carbonate plays an important role in global climate change and ocean acidification, as the precipitation and dissolution of calcium carbonate easily lead to variations in $\mathrm{pH}[4,5]$, total alkalinity [5-8], total carbon dioxide [5,9], and partial pressure of carbon dioxide $[2,4,5,10]$. In spite of the presence of continental and oceanic rock weathering and oceanic carbonate sedimentation, previous research has confirmed that the present-day ocean is in a steady state with regard to calcium [2], and the degree of $\mathrm{Ca}^{2+}$ variation is rather small. Therefore, methods for the determination of calcium in seawater with high sensitivity and accuracy are required.

Titration, as a high-precision $\mathrm{Ca}^{2+}$ determination technique, has been widely used over the past decades [11-13]. The potential interference of $\mathrm{Mg}^{2+}$, however, is the main challenge to improve the accuracy of the technique. Advanced techniques such as capillary electrophoresis [14-16], inductively coupled plasma atomic emission spectrometry [17] and mass spectrometry [18,19], can detect $\mathrm{Ca}^{2+}$ with high accuracy and precision but suffer from some intrinsic drawbacks of complicated preparation procedures, high cost, extensive laboratory experience and incapability for onsite measurements $[19,20]$. In recent years, ion-selective electrodes (ISEs) have been applied to the in situ detection of ionized calcium in seawater [21,22]. ISEs ideally operate on the basis of the Nernst equation, which predicts ca $30 \mathrm{mV}$ potential changes for a 10 -fold activity change of calcium at room temperature. Thus, a small $\mathrm{Ca}^{2+}$ activity variation (for example 10\%) can be translated into just a few millivolt (ca $1 \mathrm{mV}$ ) potential changes. Moreover, the concentrations of interfering ions such as $\mathrm{Na}^{+}(0.047 \mathrm{M}), \mathrm{Mg}^{2+}$ $(0.053 \mathrm{M})$, and $\mathrm{K}^{+}(0.010 \mathrm{M})$ in seawater are rather high. Therefore, new ISEs for the determination $\mathrm{Ca}^{2+}$ in seawater with high sensitivity and good selectivity are highly required.

With the introduction of dynamic electrochemistry protocols, ISEs can be interrogated under galvanostatic control and used for the chronopotentiometric detection in analogy to zero-current potentiometry [23]. An applied constant current pulse fully controls the ion flux from the sample into the membrane and determines the concentration of extracted ions in the phase boundary region for membranes with no intrinsic ion-exchange properties [24-27]. Besides the zero-current potential and chronopotential, the transition time has been served as an alternative readout developed by Bakker's group [28-31]. In contrast to the chronopotentiometry based on the potentials, which could be influenced by changes in the background electrolyte, the latter approach using the transition times as the analytical signals may offer linearizable calibration curves that are less prone to matrix effects [32]. The pulsed galvanostatic-controlled ion-selective sensors offer several advantages, including the capability of multianalyte detection [25,33], reversible response to polyionic compounds [34,35], drastic improvement of sensitivity [24] and selectivity [36,37]. Moreover, it has the possibility to detect activity and the total concentration of each sample simultaneously [38,39]. Interestingly, Bakker and coworkers developed a pulsed galvanostaticcontrolled ISE to obtain robust and reproducible potential readings in the super-Nernstian region, which was instrumentally adjusted and controlled [24,26]. This technique can be used for enhancing sensitivity and was developed for sensitive and selective determination of silver and calcium ions with low levels of electrolyte background [24,26]. However, to the best of our knowledge, pulsed galvanostatic-controlled ion-selective sensors based on super-Nernstian response mode have not been applied in real samples, especially those with a high-interfering background such as seawater.

Herein, a highly sensitive and selective pulsed galvanostaticcontrolled $\mathrm{Ca}^{2+}$-ISE was designed for the direct determination of calcium in seawater with enhanced sensitivity. The extraction of calcium ions from the sample side to the membrane can be assisted by the ionophore and lead to a stable and reproducible superNernstian response. The super-Nernstian region can be modulated by the magnitude and duration of the applied current pulse and other parameters. Each applied constant current pulse is followed by a baseline potential pulse to regenerate the phase boundary region of the membrane [40]. It will be shown that the proposed pulsed galvanostatic technique can be used for sensitive and selective detection of calcium in marine environment.

\section{Experimental}

\subsection{Reagents and materials}

High-molecular-weight poly(vinyl chloride) (PVC), tetradodecylammonium tetrakis(4-chlorophenyl)-borate (ETH 500), sodium tetrakis[3,3-bis(trifluoromethyl) phenyl]borate (NaTFPB), 2nitropheny octyl ether (o-NPOE), the calcium ionophore-N,Ndicyclohexyl-N',N' -dioctadecyl-3-oxapentanamide (ETH 5234) and sodium chloride $(\mathrm{NaCl}, 99.99 \%)$ were purchased from SigmaAldrich (St. Louis, MO). Calcium chloride was obtained from Macklin Biochemical (Shanghai, China) and all other chemical reagents were purchased from Sinopharm Chemical Reagent (Shanghai, China). All chemicals were analytical grade and were used without further purification. All the aqueous solutions were prepared with freshly deionized water $(18.2 \mathrm{M} \Omega \mathrm{cm}$ specific resistance) obtained with a Pall Cascada Laboratory Water System.

\subsection{Preparation of calcium ion-selective electrodes}

The calcium-selective membrane contained $1.0 \mathrm{wt} \%$ calcium ionophore (ETH 5234), $7.0 \mathrm{wt} \%$ inert lipophilic salt (ETH 500), $30 \mathrm{wt}$ $\%$ PVC, and $62 \mathrm{wt} \% o$-NPOE. The conventional calcium-selective membrane contained $1.0 \mathrm{wt} \%$ calcium ionophore (ETH 5234), 0.5. wt\% sodium tetrakis[3,3-bis(trifluoromethyl)phenyl]borate (NaTFPB), $33 \mathrm{wt} \%$ PVC, and $65.5 \mathrm{wt} \% o$-NPOE. The membrane was prepared as described before [41]. The membrane thickness was measured using a CX31-32C02 Olympus microscope (Tokyo, Japan).

For each working electrode, a disk with a $5 \mathrm{~mm}$ diameter was punched from the membranes and glued to a plastic PVC tube (i.d. $4 \mathrm{~mm}$, o. d. $6 \mathrm{~mm}$ ) with THF. $0.1 \mathrm{M} \mathrm{NaCl}$ was used as inner filling solution. Before measurements, all the working electrodes were conditioned in the same solution for $24 \mathrm{~h}$.

\subsection{EMF measurements}

All measurements were carried out at room temperature using a CHI 660 E electrochemical workstation (Shanghai Chenhua Apparatus Corporation, Shanghai, China). A conventional threeelectrode cell with an ISE as the working electrode, a platinum wire as the auxiliary electrode, and $\mathrm{Ag} / \mathrm{AgCl}(3.0 \mathrm{M} \mathrm{KCl})$ as the reference electrode was used. The activity coefficients were calculated according to the Debye-Hückel approximation. All EMF values were corrected for liquid-junction potential with the Henderson equation.

All measurements were controlled by a macro-command, which executed a series of commands in a specified order. The procedures for switching between the galvanostatic and potentiostatic steps were designed according to the macro-command dialog box to execute consecutive measurements [40]. The open-circuit potential of the electrode in $0.5 \mathrm{M} \mathrm{NaCl}$ was first recorded for $1 \mathrm{~s}$ (step 1). Then, a cathodic pulsed current of $4 \mu \mathrm{A}$ with a duration of $2 \mathrm{~s}$ was applied for step 2, which was followed by a recovery time of $100 \mathrm{~s}$ for step 3 (Scheme 1). 


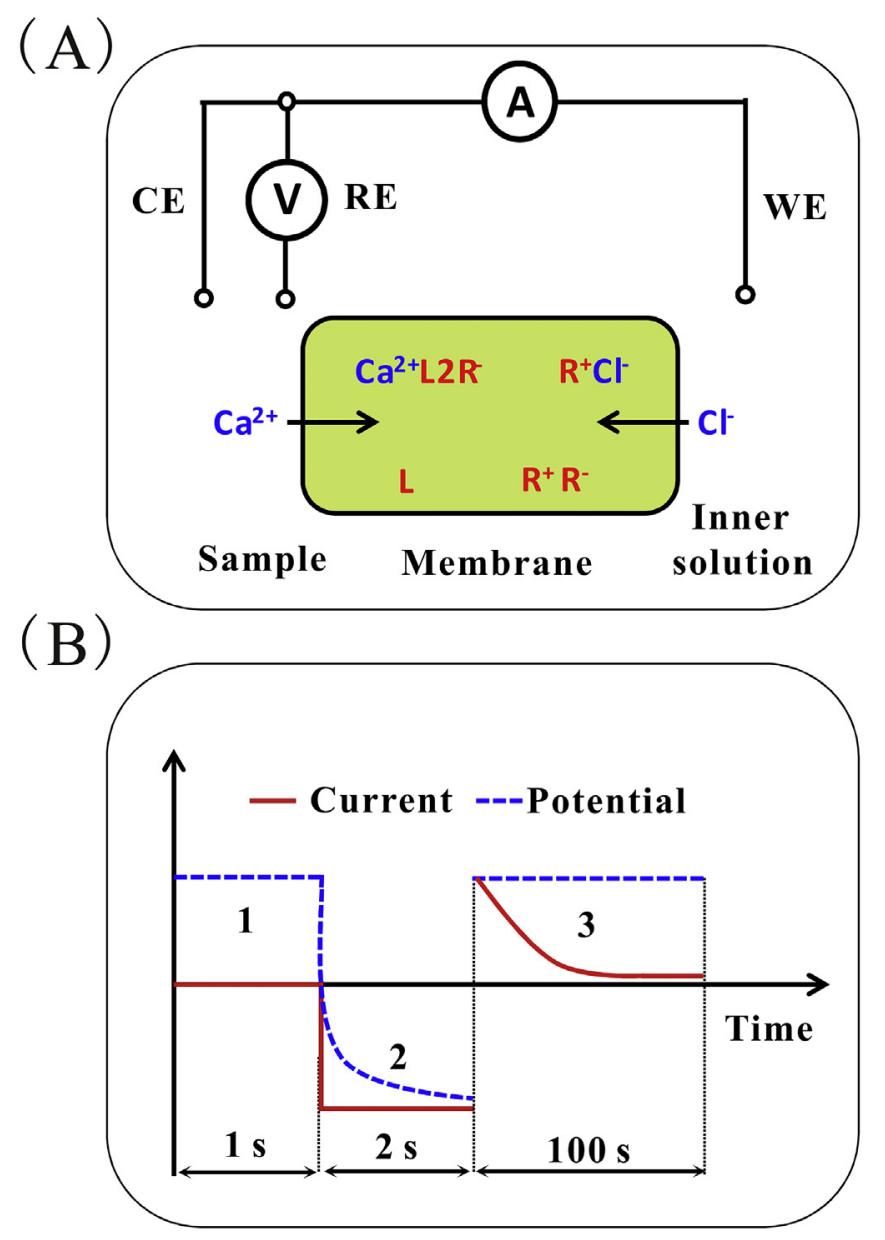

Scheme 1. (A) Schematic illustration of the sensing mechanism of $\mathrm{Ca}^{2+}$-ISE. The membrane contains calcium ionophore $(\mathrm{L})$, inert lipophilic salt $\left(\mathrm{R}^{+} \mathrm{R}^{-}\right)$without ionexchanger, and plasticizer (o-NPOE). 0.1 M NaCl was used as inner filling solution. The applied current provokes the $\mathrm{Ca}^{2+}$ into the membrane. (B) Current-time (solid line) and potential-time (dashed line) traces of the pulsed galvanostatic control of ion fluxes across the polymeric membrane calcium-selective electrode.

\subsection{Determination of calcium in seawater}

Seawater samples were collected from Bohai Sea $\left(121.0-121.3^{\circ} \mathrm{E}, 37.9-38.6^{\circ} \mathrm{N}\right.$, from surface to bottom: $\mathrm{S} 4, \mathrm{~S} 4-10 \mathrm{~m}$, S4-50 $\mathrm{m}$ and from the offshore to the open sea: S1 to S5) and Yellow Sea $\left(121.5^{\circ} \mathrm{E}, 35.0^{\circ} \mathrm{N}\right.$, from surface to bottom: S6, S6-1 m, S6-10 m, S6-20 m, and S6-38 m) on November 30, 2016 to December 3, 2016. The standard addition method was used for determination of calcium in seawater. Specifically, $30 \mathrm{~mL}$ of seawater samples was used for potential measurement at first. And then the $30 \mathrm{~mL}$ of the original seawater samples were successively spiked with $2.0 \mathrm{M}$ fresh $\mathrm{CaCl}_{2}$ solution to obtain samples containing different concentrations of calcium and the corresponding pontential values were recorded. Finally the pontential differences between the spiked and original samples and the volumes of the spiked $\mathrm{CaCl}_{2}$ were used to fit a curve and the equation as follows:

$\left(V_{x}+V_{S}\right) 10^{\Delta E / S}=c_{S} V_{s} / c_{x}+V_{x}$

Where $\Delta \mathrm{E}$ is the potential difference with and without spiked $2.0 \mathrm{M}$ fresh $\mathrm{CaCl}_{2}$ solution, $\mathrm{S}$ is the response slope of the electrode, $\mathrm{V}_{\mathrm{x}}$ and $\mathrm{V}_{\mathrm{s}}$ are the volumes of the original and the spiked $\mathrm{CaCl}_{2}$, and the $\mathrm{c}_{\mathrm{S}}$ is the spiked $\mathrm{CaCl}_{2}$ concentration which equals to $2.0 \mathrm{M}$. And the concentration of $\mathrm{Ca}^{2+}\left(\mathrm{c}_{\mathrm{x}}\right)$ in seawater was obtained from the values of added $\mathrm{CaCl}_{2}$ concentration over the slope of the curve. Inductively coupled plasma atomic emission spectrometry (ICP-AES, Perkin Eimer optima 7000DV) was utilized as reference method to detect $\mathrm{Ca}^{2+}$ in seawater. For the calcium detection using ICP-AES, seawater samples were acidified to $\mathrm{pH} 2.0$ with $\mathrm{HNO}_{3}$ and stored at $4{ }^{\circ} \mathrm{C}$ before analysis.

\section{Results and discussion}

In this work, a galvanostatically controlled ISE was designed for chronopotentiometric detection of $\mathrm{Ca}^{2+}$. Scheme $1 \mathrm{~A}$ shows that the $\mathrm{Ca}^{2+}$-selective membrane containing lipophilic salt ETH 500 instead of traditional ion-exchanger is galvanostatically controlled. By applying an constant cathodic current pulse (step 2 in Scheme $1 \mathrm{~B})$, the calcium ions were extracted from the sample into the membrane to produce a chronopotential response. It should be noted that the $\mathrm{Cl}^{-}$could be extracted into the membrane in the opposite direction during the cathodic current pulse. However, in the presence of ionophore for $\mathrm{Ca}^{2+}$, the applied cathodic current mainly forces the extraction of the calcium ions. As illustrated in Scheme 1B, the current pulse based $\mathrm{Ca}^{2+}$-ISE was operated by the
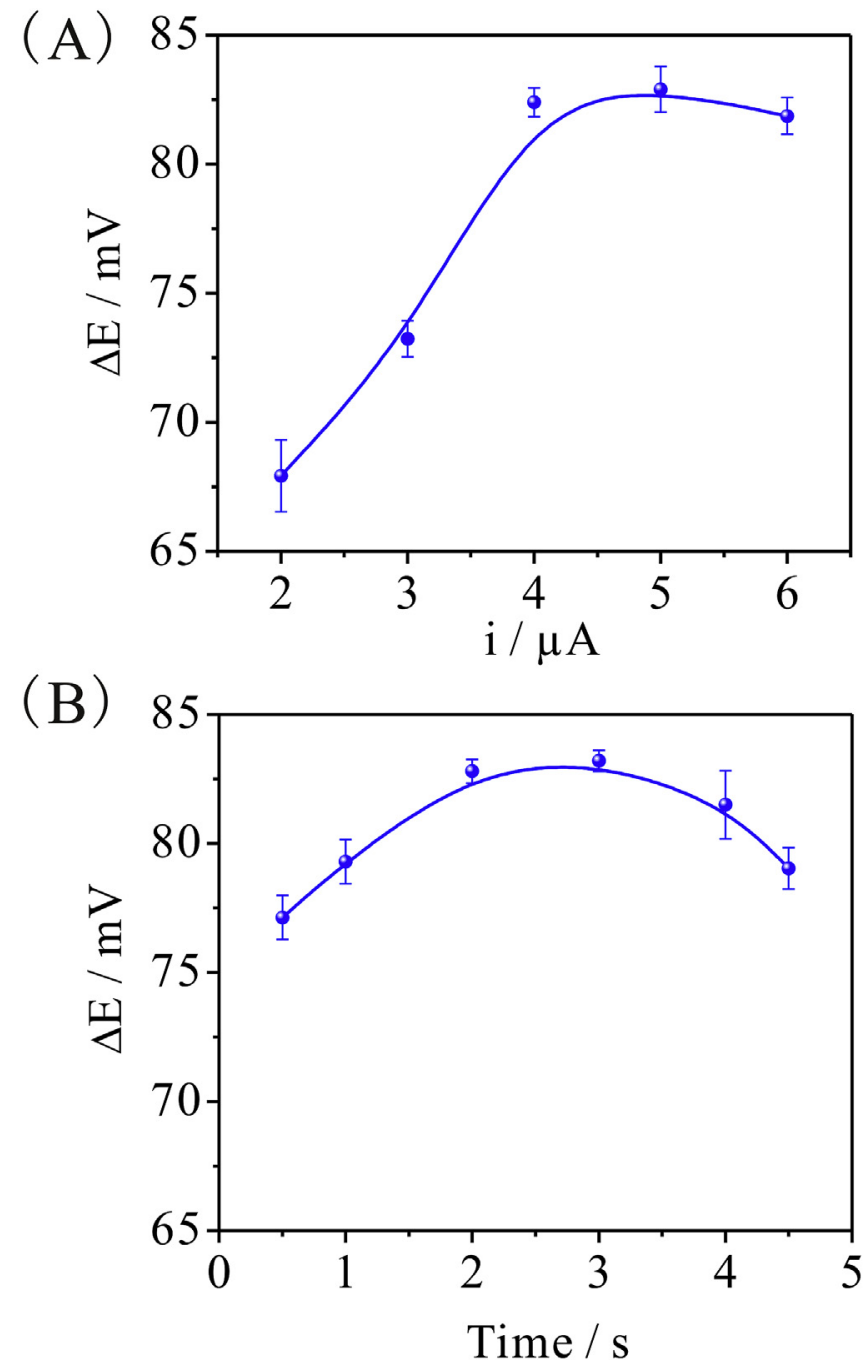

Fig. 1. Effects of the current amplitude (A) and current pulse duration (B) on the potential difference for measuring $10^{-2.5}$ and $10^{-1.5} \mathrm{M} \mathrm{Ca}^{2+}$ with $0.5 \mathrm{M} \mathrm{NaCl}$ background. Error bars represent one standard deviation for three measurements. 
combination of both galvanostatic and potentiostatic steps [40]. After the open-circuit potential of the electrode in $0.5 \mathrm{M} \mathrm{NaCl}$ was first recorded for $1 \mathrm{~s}$ (step 1 ), a constant cathodic pulsed current of $4 \mu \mathrm{A}$ with a duration of $2 \mathrm{~s}$ was applied (step 2), and the applied current pulse could lead to the extraction of the calcium ions into the membrane to produce a chronopotential response. At last, a controlled voltage at the open-circuit potential was followed for $100 \mathrm{~s}$ which enable the recovery of the membrane (step 3). The potential difference $(\Delta \mathrm{E})$ between the open-circuit potential of step 1 and the potential measured at $2 \mathrm{~s}$ of step 2 was used for quantification.

\subsection{Effects of magnitude and duration of the applied current pulse on potential change}

At lower calcium concentrations, polarization in the aqueous diffusion layer near the membrane exists. Both calcium and background sodium ions can be extracted into membrane, which leads to the super-Nernstian response. One unique feature of the current pulse based ISEs is that the super-Nernstian region of the electrode can be modulated by magnitude of current and its duration time in a single pulse [26]. Previous research has shown that the position of the super-Nernstian jump depends on the current pulse parameters, the selectivity of the pulstrode and the concentration of interfering ions [24]. A position shift to higher concentrations was expected and observed with the increases of the magnitude of current and its duration time (see below). The effect of the pulsed cathodic current on the potential difference between the calcium concentrations of $10^{-2.5}$ and $10^{-1.5} \mathrm{M}$ was tested. As shown in Fig. 1A, the potential difference increases with the tested cathodic current amplitude from 2 to $4 \mu \mathrm{A}$ and then reaches a plateau thereafter. When a larger cathodic pulsed current is applied through the polymeric membrane, the background ions or oppositely charged ions could be extracted along with the calcium into the membrane, which may deteriorate the selectivity of the electrode [25]. The duration of the applied current is also a key parameter to affect the potential difference. The duration of the applied current from 0.5 to $4.5 \mathrm{~s}$ was investigated. As depicted in Fig. 1B, the potential difference increases with the test time from 0.5 to $2 \mathrm{~s}$. Further increasing the duration may deteriorate the selectivity and result in a decreased membrane potential. Therefore, the cathodic current amplitude of $4 \mu \mathrm{A}$ with a pulse duration of $2 \mathrm{~s}$ was selected for subsequent experiments.

It should be noted that at a given current, the fluxes of the calcium cannot sustain the imposed current, so that the depletion of the calcium concentration can be observed and visualized as a transition in the recorded signal over time [31]. At high concentration of calcium (concentrations of $10^{-2.5}-10^{-1.5} \mathrm{M}$ ), calcium depletion was not observed for the chosen current amplitudes (at $4 \mu \mathrm{A}$ with a pulse duration of $2 \mathrm{~s}$ ). However, as shown in Fig. 2, a transition can be observed with increase in the duration time (Fig. 2A and B) and/or at higher current densities (Fig. 2C and D). It should be noted that the parameters could be optimized to achieve the time resolved chronopotentiometric ion sensing.

\subsection{Effect of ETH 500 on the potential response}

ETH 500, as a kind of ionic liquid, could decrease the membrane resistance and influence the activity coefficient in the membrane [35]. Moreover importantly, the amount of ETH dictates, via electromigration of the ion exchanger part, to some extent the response of the electrode. The potential responses of the calcium-sensitive membrane with different amounts of ETH 500 were tested. As depicted in Fig. 3A, the responses of the calcium-selective
(A)

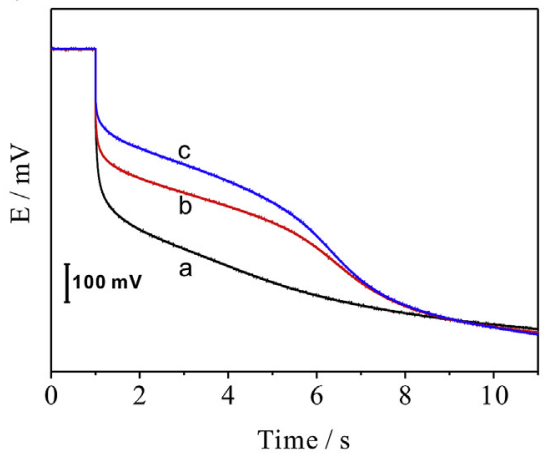

(C)

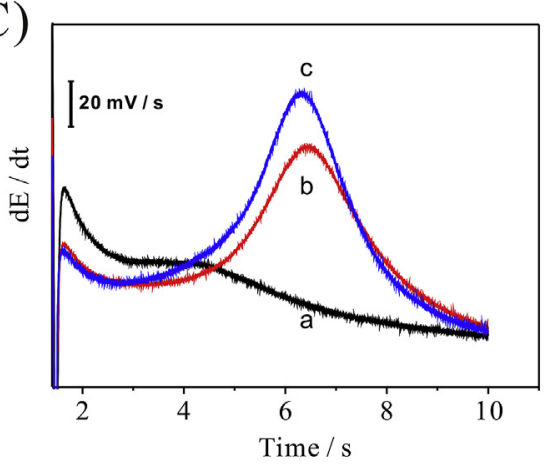

(B)

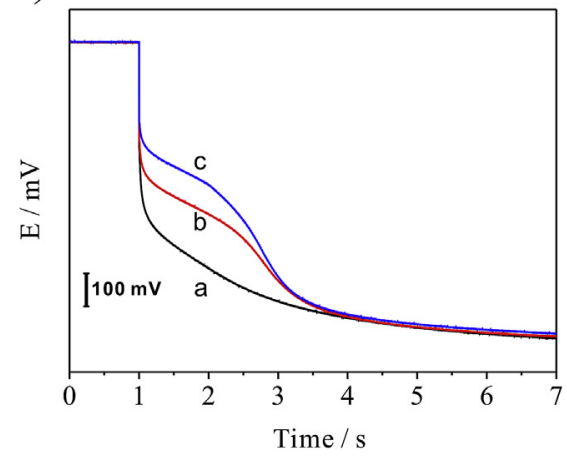

(D)

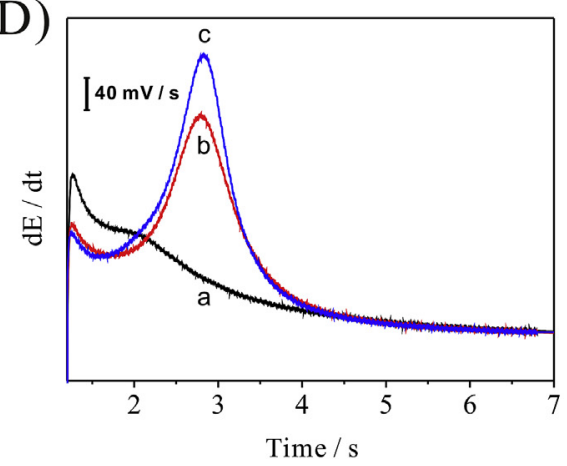

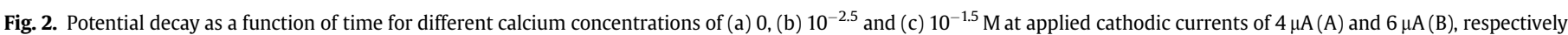

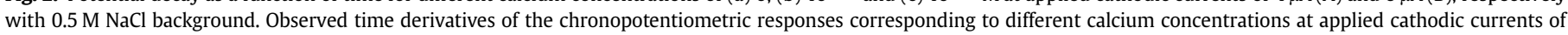
$4 \mu \mathrm{A}(\mathrm{C})$ and $6 \mu \mathrm{A}(\mathrm{D})$, respectively. 
membrane with different ETH 500 contents are almost identical in terms of linear range and detection limit. However, the potential difference between the concentrations of $10^{-2.5}$ and $10^{-1.5} \mathrm{M} \mathrm{Ca}^{2+}$ was different (Fig. 3B). When the content of ETH 500 is low, such as $1 \mathrm{wt} \%$ and $3 \mathrm{wt} \%$, the potential responses were unstable and lead to a big noise. In the presence of higher concentration of ETH 500, the potential responses of the membrane with $7 \mathrm{wt} \%$ ETH 500 are much more stable than that of the membrane with $5 \mathrm{wt} \%$ ETH 500 though the potential differences between the concentrations of $10^{-2.5}$ and $10^{-1.5} \mathrm{M} \mathrm{Ca}^{2+}$ are in consistency with each other. When the content of ETH 500 in the membrane is up to $10 \mathrm{wt} \%$, the potential difference decreases though a stable response, which is in accordance with the previous study [35]. Therefore, as a compromise between stability and sensitivity, $7 \mathrm{wt} \%$ ETH 500 was selected as the appropriate content in the calcium-selective membrane.

\subsection{Selectivity of the proposed sensor}

Selectivity is also an essential factor to access the sensing system for $\mathrm{Ca}^{2+}$ detection. Moreover, the super-Nernstian region depends on
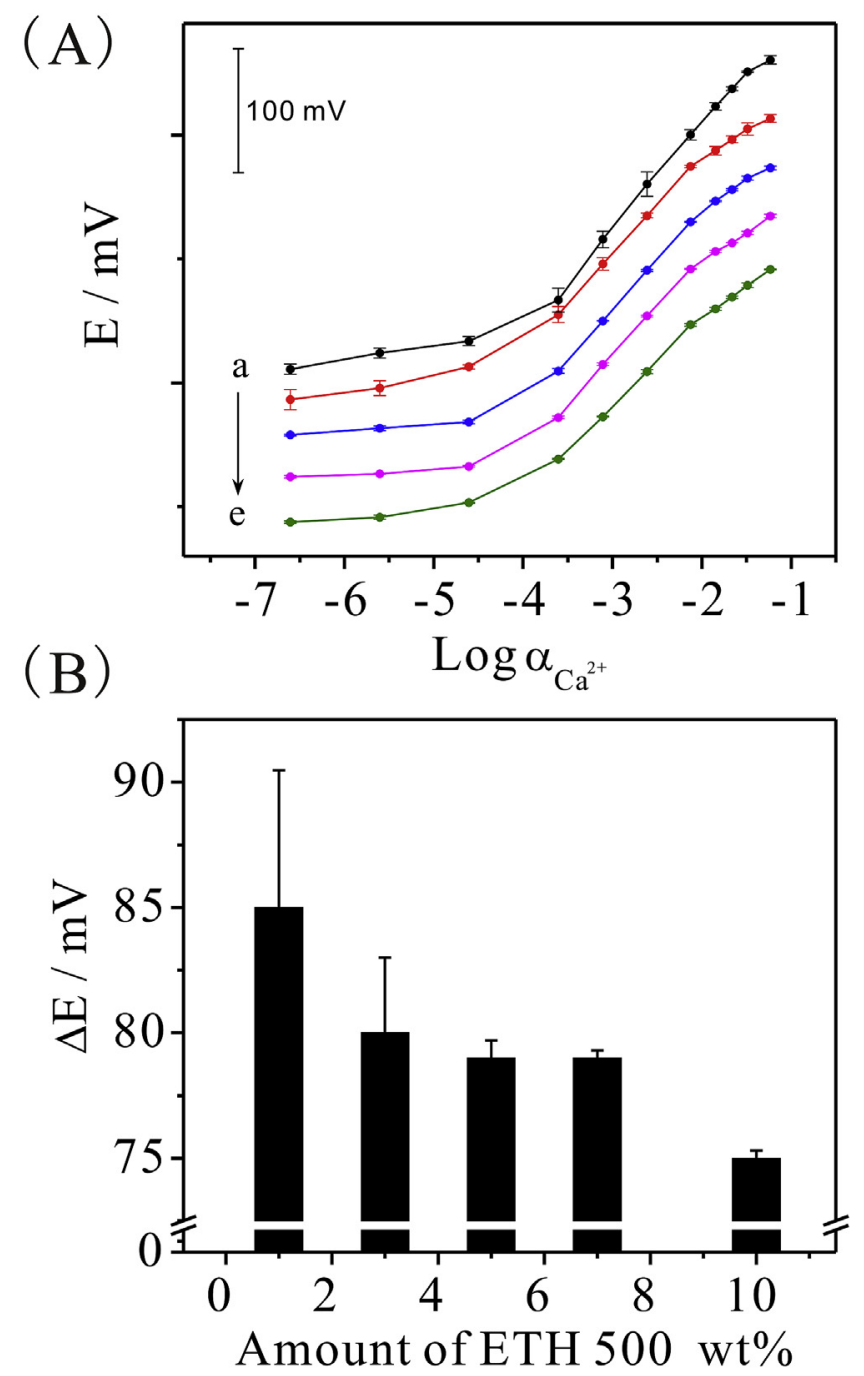

Fig. 3. (A) Effect of the amount of lipophilic salt ETH 500 in the membrane (a) 1, (b) 3 (c) 5 , (d) 7 , and (e) $10 \mathrm{wt} \%$ ETH 500 on the potential response to calcium. (B) Potential difference between the concentrations of calcium $10^{-2.5}$ and $10^{-1.5} \mathrm{M}$. Measurements were done by using a cathodic pulsed current of $4 \mu \mathrm{A}$ with a duration of $2 \mathrm{~s}$ in $0.5 \mathrm{M}$ $\mathrm{NaCl}$ background. Error bars represent one standard deviation for three measurements. the selectivity of the electrode. The selectivity of the pulsed galvanostatic-controlled Ca-ISE were characterized by using a separate solution method to evaluate the influences of the interfering ions [42]. As shown in Fig. 4, the response slopes of the galvanostatically controlled Ca-ISEs toward the main and discriminated ions at high activities remain close to the Nernstian response, and the selectivity coefficients were calculated as $\log K_{\mathrm{Ca}, \mathrm{Na}}^{\mathrm{pot}}=-7.7 \pm 0.2, \quad \log K_{\mathrm{Ca}, \mathrm{Mg}}^{\text {pot }}=$ $-8.5 \pm 0.2, \quad \log K_{C a, K}^{p o t}=-9.3 \pm 0.3$. These coefficients are in agreement with previous findings that the improvement in selectivity could be attributed to complete elimination of transmembrane ion fluxes in the pulsed galvanostatic-controlled Ca-ISEs [37]. Additionally, such an obvious comparison in the selectivity coefficients demonstrates that the pulsed galvanostatic-controlled Ca-ISE is sufficient for the determination of calcium in seawater.

\subsection{Performance of the proposed sensor}

Under the optimized experimental conditions, the analytical performance of the pulsed galvanostatic-controlled ISEs for quantitative detection of calcium was evaluated with various activities of $\mathrm{Ca}^{2+}$. At high concentration of calcium (concentrations of $10^{-2.5}-10-{ }^{1.5} \mathrm{M}$ ), the current-induced ion fluxes are dominantly maintained by the calcium ions. Fig. $5 \mathrm{~A}$ shows that the potential change is proportional to the activity of calcium in the range of $7.8 \times 10^{-4}-7.5 \times 10^{-3} \mathrm{M}$ and the electrode shows a superNernstian response with a slope of $82.3 \pm 0.5 \mathrm{mV} /$ decade and a correlation coefficient $\left(R^{2}\right)$ of 0.9992 (Fig. 5B). Since the activity of calcium in the seawater is about $2.4 \times 10^{-3} \mathrm{M}$ (concentration about $0.01 \mathrm{M})$, a large change in potential occurs when the concentration of calcium ion changes in seawater. Therefore, the proposed method has the potential for the detection of calcium in the seawater with high sensitivity.

\subsection{Effects of salinity and temperature}

Even though seawater salinity is quite constant, there are variations of $\mathrm{NaCl}$ for coastal seawaters. In this study, the chronopotential responses of the electrode with different concentrations of $\mathrm{NaCl}$ were tested (Fig. 6). As expected, the maximum super-Nernstian region could be extended with higher

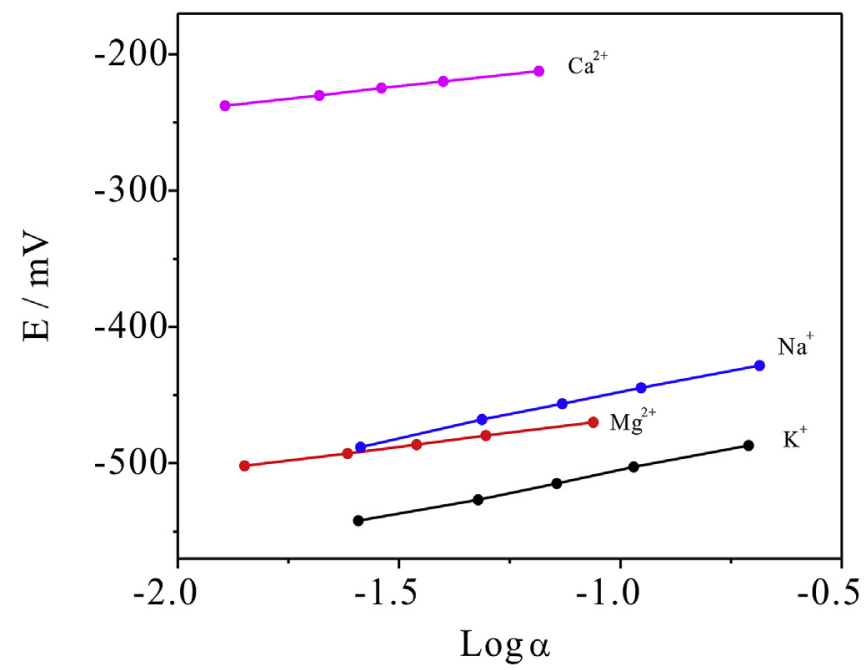

Fig. 4. Responses of Ca-selective electrode toward unbuffered chloride salts of $\mathrm{Ca}^{2+}$ (slope $35.7 \mathrm{mV} / \mathrm{dec}$ ) and interfering ions of $\mathrm{Mg}^{2+}$ (slope $39.3 \mathrm{mV} / \mathrm{dec}$ ), $\mathrm{Na}^{+}$(slope 64.9 $\mathrm{mV} / \mathrm{dec}$ ), and $\mathrm{K}^{+}$(slope $62.0 \mathrm{mV} / \mathrm{dec}$ ). Ca-ISEs are conditioned in $0.1 \mathrm{M} \mathrm{NaCl}$ solution. Measurements were done by a cathodic pulsed current of $4 \mu \mathrm{A}$ with a duration of $2 \mathrm{~s}$ and $7 \mathrm{wt} \%$ of ETH 500 in the membrane. 

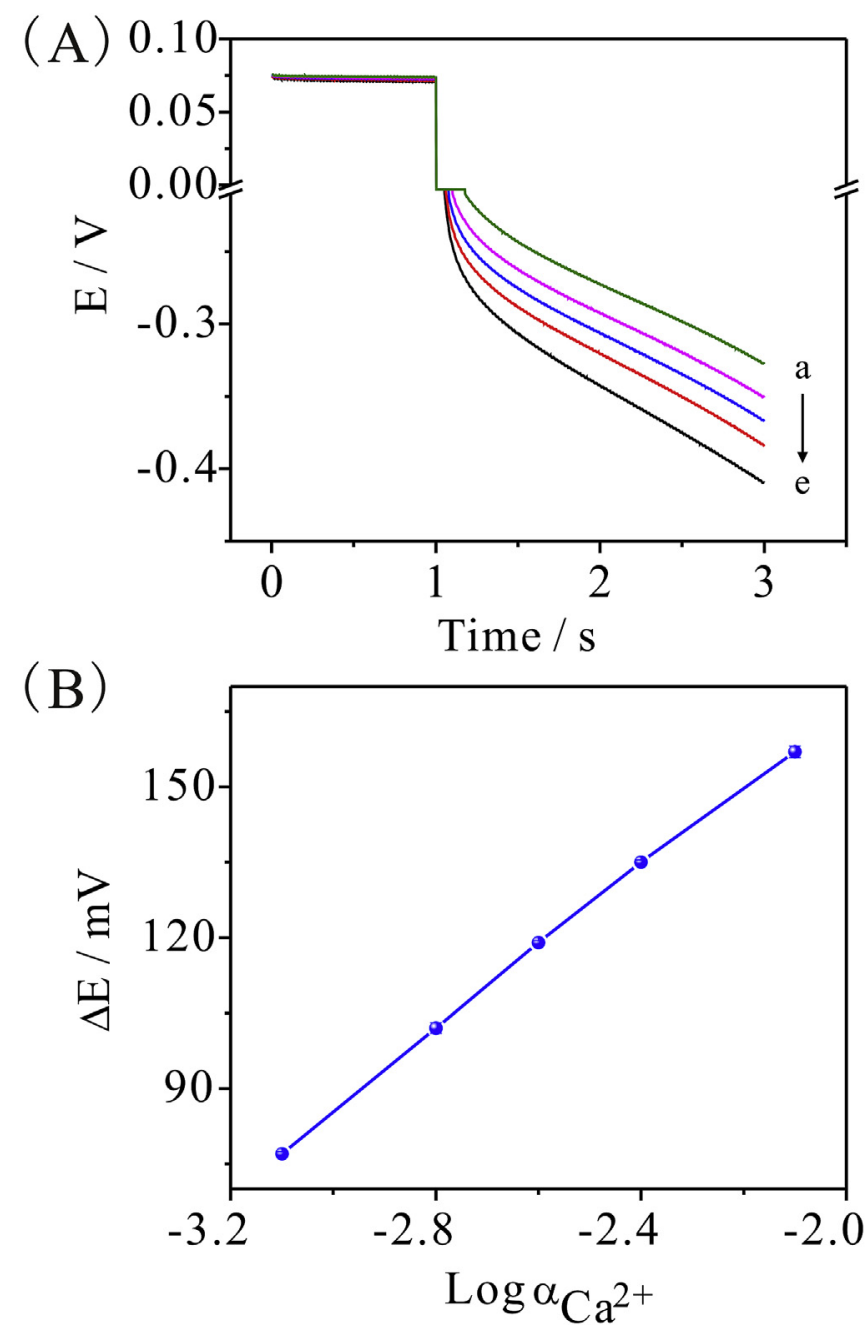

Fig. 5. (A) Potentiometric responses of the proposed method for detecting various activities of $\mathrm{Ca}^{2+}$ in $0.5 \mathrm{M} \mathrm{NaCl}$ : (a) $7.5 \times 10^{-3}$, (b) $3.8 \times 10^{-3}$, (c) $2.4 \times 10^{-3}$, (d) $1.5 \times 10^{-3}$, and (e) $7.8 \times 10^{-4} \mathrm{M}$. (B) Corresponding calibration curve. Measurements were done by a cathodic pulsed current of $4 \mu \mathrm{A}$ with a duration of $2 \mathrm{~s}$ in $0.5 \mathrm{M} \mathrm{NaCl}$ background and $7 \mathrm{wt} \%$ of ETH 500 in the membrane. Error bars represent the standard deviations of three parallel measurements.

background ions. While maximum sample polarization occurs at lower concentrations, the proposed Ca-ISE exhibits a superNernstian response between the calcium concentrations of $10^{-2.5}-10^{-1.5} \mathrm{M}$ with high concentrations of background ions.

The electrode slope and some membrane formulations are known to be temperature dependent $[43,44]$. Thus, the temperature dependence on the electrode's calcium sensitivity was investigated from 4 to $30^{\circ} \mathrm{C}$ at an interval of $5^{\circ} \mathrm{C}$. Indeed, an increase in the sensitivity with increase in the temperature was observed. The increase is ca $2 \mathrm{mV}$ with a temperature increase of $10^{\circ} \mathrm{C}$. It should be noted that the IR drop should be taken into consideration at the lower temperatures (data are not shown).

\subsection{Reproducibility of the proposed sensor}

The stability of the Ca-ISE was evaluated by measuring the response to $\mathrm{Ca}^{2+}$ at the activity of $10^{-3.1} \mathrm{M}$. Previous report has shown that the duration of the potential baseline pulse is usually 30-50 times longer than that of the current pulse to ensure that the ions are extracted effectively for the regenerated membrane [25]. In this work, each current pulse was followed by a $100 \mathrm{~s}$ baseline

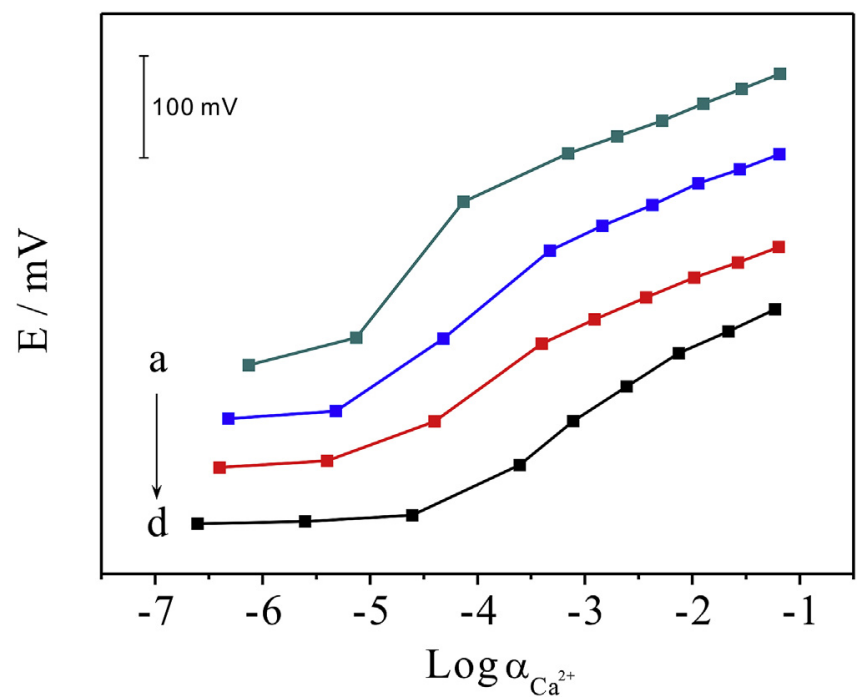

Fig. 6. Potentiometric responses of the electrode to calcium in the background solutions of (a) 0.005 , (b) 0.05 , (c) 0.1 and (d) $0.5 \mathrm{M} \mathrm{NaCl}$. Error bars represent one standard deviation for three measurements.

potential pulse. As shown in Fig. 7, the potential readings were reproducible from pulse to pulse. The reversibility of the Ca-ISE were evaluated by measuring the potential difference between the concentrations of calcium $10^{-2.5}-10^{-1.5}$ (the results are not shown). Experiments revealed that the signal changes were fully reversible and the electrode could be used for consecutive measurements.

\subsection{Seawater analysis}

To validate the feasibility and practicability of the proposed methodology, seawater samples from Bohai $\left(121.0-121.3^{\circ} \mathrm{E}\right.$, $\left.38.1-38.6^{\circ} \mathrm{N}\right)$ and Yellow Seas $\left(121.5^{\circ} \mathrm{E}, 35.0^{\circ} \mathrm{N}\right)$ were analyzed using the standard addition method. The average concentrations as well as the standard deviation of calcium measurements in real seawater were measured by using two kinds of Ca-ISEs and ICP-AES

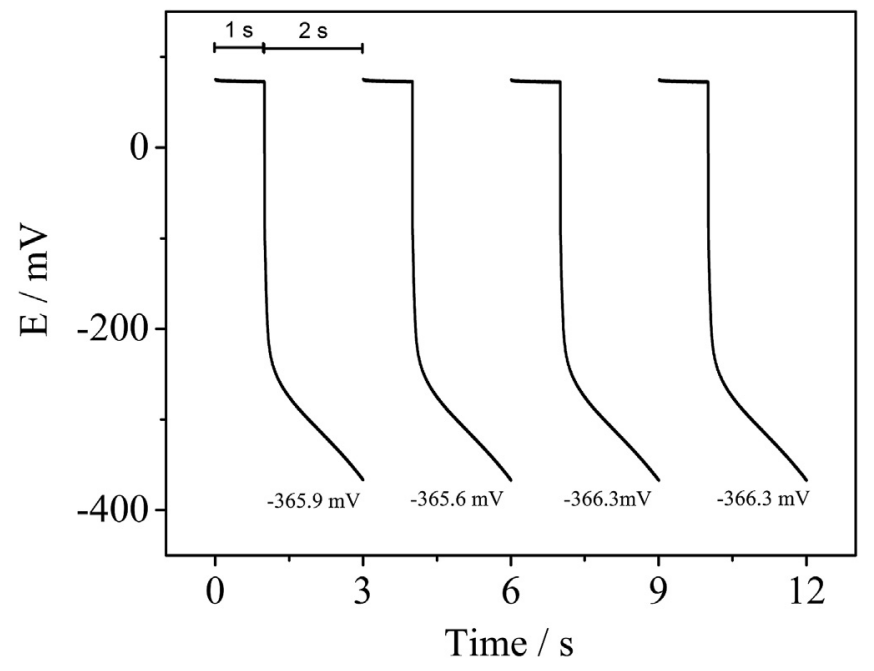

Fig. 7. Reproducibility of the Ca-ISE in $0.5 \mathrm{M} \mathrm{NaCl}$ background. Each pulse sequence at zero current for $1 \mathrm{~s}$ and at $4 \mu \mathrm{A}$ for $2 \mathrm{~s}$, and the $100 \mathrm{~s}$ potential baseline pulse is not shown on the plot. Measurements were done by a cathodic pulsed current of $4 \mu \mathrm{A}$ with a duration of $2 \mathrm{~s}$ in $0.5 \mathrm{M} \mathrm{NaCl}$ background and $7 \mathrm{wt} \%$ of ETH 500 in the membrane. 
Table 1

Results of determination of calcium in seawater samples ${ }^{\mathrm{a}}$.

\begin{tabular}{|c|c|c|c|c|}
\hline Seawater sample & & ICP-AES (g/L) & Conventional Ca-ISE (g/L) & This work $(\mathrm{g} / \mathrm{L})$ \\
\hline \multirow[t]{7}{*}{ Bohai Sea } & $\mathrm{S} 1$ & $0.372 \pm 0.021$ & $0.367 \pm 0.027$ & $0.375 \pm 0.022$ \\
\hline & $\mathrm{S} 2$ & $0.389 \pm 0.012$ & $0.382 \pm 0.086$ & $0.386 \pm 0.027$ \\
\hline & S3 & $0.386 \pm 0.010$ & $0.377 \pm 0.025$ & $0.394 \pm 0.016$ \\
\hline & S4 & $0.389 \pm 0.020$ & $0.391 \pm 0.050$ & $0.390 \pm 0.036$ \\
\hline & $\mathrm{S} 4-10 \mathrm{~m}$ & $0.383 \pm 0.014$ & $0.387 \pm 0.024$ & $0.384 \pm 0.017$ \\
\hline & $\mathrm{S} 4-50 \mathrm{~m}$ & $0.385 \pm 0.013$ & $0.388 \pm 0.022$ & $0.382 \pm 0.030$ \\
\hline & S5 & $0.393 \pm 0.018$ & $0.391 \pm 0.031$ & $0.385 \pm 0.030$ \\
\hline \multirow[t]{5}{*}{ Yellow Sea } & S6 & $0.398 \pm 0.019$ & $0.387 \pm 0.021$ & $0.391 \pm 0.010$ \\
\hline & $\mathrm{S} 6-1 \mathrm{~m}$ & $0.393 \pm 0.015$ & $0.392 \pm 0.027$ & $0.397 \pm 0.013$ \\
\hline & S6-5 m & $0.397 \pm 0.017$ & $0.388 \pm 0.025$ & $0.394 \pm 0.026$ \\
\hline & S6-20 m & $0.395 \pm 0.013$ & $0.402 \pm 0.051$ & $0.401 \pm 0.028$ \\
\hline & $\mathrm{S} 6-38 \mathrm{~m}$ & $0.389 \pm 0.015$ & $0.392 \pm 0.047$ & $0.396 \pm 0.025$ \\
\hline
\end{tabular}

${ }^{\mathrm{a}}$ Mean \pm standard deviation $(\mathrm{n}=3)$.

as a reference method (see Table 1 ). The average concentrations of calcium detected by the proposed Ca-ISEs are in agreement with the concentration of the two other methods. The results show that on the whole, the concentration of calcium in the Yellow sea was higher than that in Bohai sea, which is probably due to the presence of the relatively high concentrations of organic matter in Bohai sea $[45,46]$. Since the near shore areas were easily affected by the terrestrial inputs, including runoff and human activities, the calcium concentration of S1 (near shore area) was lower than those of off shore areas (S2-S5). The vertical variations of calcium concentration in the Yellow seas (S6) and Bohai (S4) were slight. All these results demonstrate that the proposed electrode could be effectively used for the measurement of calcium in seawater.

\section{Conclusions}

The pulsed galvanostatic controlled technique was applied for the measurement of calcium in seawater. The proposed method offers a series of advantages over other methods for calcium determination in seawater. First, in contrast to the conventional CaISE with the Nernstian response (i.e. ca $29.2 \mathrm{mV} / \mathrm{dec}$ ), the present sensor exhibits a high sensitivity when the super-Nernstian response approaches about $80 \mathrm{mV}$ for calcium measurements in the activity range of $7.8 \times 10^{-4}-7.5 \times 10^{-3} \mathrm{M} \mathrm{CaCl}_{2}$ in seawater. Second, compared with the titration of calcium and the conventional Ca-ISE, the present sensor suppresses the interference of $\mathrm{Mg}^{2+}$ effectively and an ideal selectivity which is sufficient to determine calcium in seawater was obtained. Third, our proposed pulsed galvanostatically controlled Ca-ISEs allow for the sensitive measurement of calcium in seawater samples without the need for any pretreatment procedures, even dilution. Moreover, zerocurrent potential, chronopotential or transition time can be served as the analytical signals for the current pulse based ionselective electrodes. It is anticipated that the proposed method is promising for seawater analysis.

\section{Acknowledgements}

This work was financially supported by the National Natural Science Foundation of China $(21575158,21677172)$, the Instrument Developing Project of the Chinese Academy of Sciences (Y728021021), The National Key Research and Development Program of China (No. 2016YFC1400700), the CAS Youth Innovation Promotion Association (2014190) and the Taishan Scholar Program of Shandong Province (TS20081159).

\section{References}

[1] K.A. Matthews, A.G. Grottoli, W.F. McDonough, J.E. Palardy, Upwelling, species, and depth effects on coral skeletal cadmium-to-calcium ratios $(\mathrm{Cd} / \mathrm{Ca}), \mathrm{Geo}-$ chem. Cosmochim. Acta 72 (2008) 4537-4550.

[2] A.D. Schmitt, F. Chabaux, P. Stille, The calcium riverine and hydrothermal isotopic fluxes and the oceanic calcium mass balance, Earth Planet Sci. Lett. 213 (2003) 503-518.

[3] R. Hernandez, J. Riu, F.X. Rius, Determination of calcium ion in sap using carbon nanotube-based ion-selective electrodes, Analyst 135 (2010) 1979-1985.

[4] C.L. De La Rocha, D.J. DePaolo, Isotopic evidence for variations in the marine calcium cycle over the cenozoic, Science 289 (2000) 1176-1178.

[5] T. Ilyina, D. Wolf-Gladrow, G. Munhoven, C. Heinze, Assessing the potential of calcium-based artificial ocean alkalinization to mitigate rising atmospheric $\mathrm{CO}_{2}$ and ocean acidification, Geophys. Res. Lett. 40 (2013) 5909-5914.

[6] L.J.A. Murillo, P.L. Jokiel, M.J. Atkinson, Alkalinity to calcium flux ratios for corals and coral reef communities variances between isolated and community conditions, Peer-Reviewed J 2 (2014) e249.

[7] F. Gazeau, L. Urbini, T.E. Cox, S. Alliouane, J.P. Gattuso, Comparison of the alkalinity and calcium anomaly techniques to estimate rates of net calcification, Mar. Ecol. Prog. Ser. 527 (2015) 1-12.

[8] K.L. Middlemiss, M.A. Urbina, R.W. Wilson, Effects of seawater alkalinity on calcium and acid-base regulation in juvenile European lobster (Homarus gammarus) during a moult cycle, Comp. Biochem. Physiol. Mol. Integr. Physiol. 193 (2016) 22-28.

[9] R.M. Coggon, D.A.H. Teagle, Hydrothermal calcium-carbonate veins reveal past ocean chemistry, Trac-Trends Anal. Chem. 30 (2011) 1252-1268.

[10] G. Falini, S. Fermani, G. Tosi, E. Dinelli, Calcium carbonatemorphology and structure in the presence of seawater Ions and humic acids, Cryst. Growth Des. 9 (2009) 2065-2072.

[11] B.S. Krumgalz, R. Holzer, On the determination of $\mathrm{Ca}^{2+}$ ion concentration in seawater, Limnol. Oceanogr. 25 (1980) 367-370.

[12] E.J. Olson, C.T.A. Chen, Interference in the determination of calcium in seawater, Limnol. Oceanogr. 27 (1982) 375-380.

[13] S. Karita, T. Kaneta, Chelate titrations of $\mathrm{Ca}^{2+}$ and $\mathrm{Mg}^{2+}$ using microfluidic paper-based analytical devices, Anal. Chim. Acta 924 (2016) 60-67.

[14] T. Wang, H. Kee Lee, S.F. Yau Li, Determination of sodium, potassium, magnesium, and calcium in seawater by capillary electrophoresis withindirect photometric detection, J. Liq. Chromatogr. Relat. Technol. 21 (1998) 2485-2496.

[15] K. Fukushi, K. Hiiro, Determination of magnesium and calcium in seawater, Fresenius' J. Anal. Chem. 323 (1986) 44-46.

[16] K. Fukushi, K. Hiiro, Determination of magnesium and calcium ions in seawater by capillary zone electrophoresis, Fresenius' J. Anal. Chem. 356 (1996) 150-154.

[17] C. Gueguen, J. Dominik, D. Perret, Use of chelating resins and inductively coupled plasma mass spectrometry for simultaneous determination of trace and major elements in small volumes of saline water samples, Fresenius' J. Anal. Chem. 370 (2001) 909-912.

[18] P. Rodriguez-Gonzalez, J.M. Marchante-Gayon, J.I.G. Alonso, A. Sanz-Medel, Isotope dilution analysis for elemental speciation: a tutorial review, Spectrochim. Acta, Part B 60 (2005) 151-207.

[19] J. Vogl, W. Pritzkow, Isotope dilution mass spectrometry - a primary method of measurement and its role for RM certification, J. Metrol. Soc. India 25 (2010) 135-164.

[20] A.M. Beltagi, E.M. Ghoneim, M.M. Ghoneim, Simultaneous determination of cadmium (II), lead (II), copper (II) and mercury (II) by square-wave anodic stripping voltammetry at a montmorillonite-calcium modified carbon paste electrode, Int. J. Environ. Anal. Chem. 91 (2011) 17-32.

[21] H. Xu, Y. Wang, Z.Y. Luo, Y.W. Pan, A miniature all-solid-state calcium electrode applied to in situ seawater measurement, Meas. Sci. Technol. 24 (2013). 
[22] M. Cuartero, N. Pankratova, T. Cherubini, G.A. Crespo, F. Massa, F. Confalonieri, E. Bakker, In situ detection of species relevant to the carbon cycle in seawater with submersible potentiometric probes, Environ. Sci. Technol. Lett. 4 (2017) 410-415.

[23] E. Bakker, Enhancing ion-selective polymeric membrane electrodes by instrumental control, Trac. Trends Anal. Chem. 53 (2014) 98-105.

[24] S. Makarychev-Mikhailov, A. Shvarev, E. Bakker, Calcium pulstrodes with 10 fold enhanced sensitivity for measurements in the physiological concentration range, Anal. Chem. 78 (2006) 2744-2751.

[25] A. Shvarev, E. Bakker, Pulsed galvanostatic control of ionophore-based polymeric ion sensors, Anal. Chem. 75 (2003) 4541-4550.

[26] S. Makarychev-Mikhailov, A. Shvarev, E. Bakker, Pulstrodes: triple pulse control of potentiometric sensors, J. Am. Chem. Soc. 126 (2004) 10548-10549.

[27] N.N. Yu, J.W. Ding, W.W. Wang, X.D. Wang, W. Qin, Pulsed galvanostatic control of a solid-contact ion-selective electrode for potentiometric biosensing of microcystin-LR, Sensor. Actuator. B 230 (2016) 785-790.

[28] M.G. Afshar, G.A. Crespo, E. Bakker, Direct ion speciation analysis with ionselective membranes operated in a sequential potentiometric/time resolved chronopotentiometric sensing mode, Anal. Chem. 84 (2012) 8813-8821.

[29] G.A. Crespo, M.G. Afshar, E. Bakker, Direct detection of acidity, alkalinity, and pH with membrane electrodes, Anal. Chem. 84 (2012) 10165-10169.

[30] G.A. Crespo, M.G. Afshar, E. Bakker, Reversible sensing of the anticoagulant heparin with protamine permselective membranes, Angew. Chem. Int. Ed. 51 (2012) 12575-12578.

[31] Z. Jarolímová, G.A. Crespo, X.J. Xie, M.G. Afshar, M. Pawlak, E. Bakker, Chronopotentiometric carbonate detection with all-solid-state ionophore-based electrodes, Anal. Chem. 86 (2014) 6307-6314.

[32] M.G. Afshar, G.A. Crespo, E. Bakker, Flow chronopotentiometry with ionselective membranes for cation, anion, and polyion detection, Anal. Chem. 88 (2016) 3945-3952.

[33] J.W. Ding, N.N. Yu, X.D. Wang, W. Qin, Sequential and selective detection of two molecules with a single solid-contact chronopotentiometric ion-selective electrode, Anal. Chem. 90 (2018) 1734-1739.

[34] K.L. Gemene, M.E. Meyerhoff, Reversible detection of heparin and other polyanions by pulsed chronopotentiometric polymer membrane electrode, Anal. Chem. 82 (2010) 1612-1615.
[35] Y. Chen, J.W. Ding, W. Qin, Polycation-sensitive membrane electrode for determination of heparin based on controlled release of protamine, Analyst 137 (2012) 1944-1949.

[36] H. Perera, A. Shvarev, Unbiased selectivity coefficients obtained for the pulsed chronopotentiometric polymeric membrane ion sensors, J. Am. Chem. Soc. 129 (2007) 15754-15755.

[37] H. Perera, A. Shvarev, Determination of unbiased selectivity coefficients using pulsed chronopotentiometric polymeric membrane ion sensors, Anal. Chem. 80 (2008) 7870-7875.

[38] A. Shvarev, E. Bakker, Distinguishing free and total calcium with a single pulsed galvanostatic ion-selective electrode, Talanta 63 (2004) 195-200.

[39] K.L. Gemene, E. Bakker, Measurement of total calcium by flash chronopotentiometry at polymer membrane ion-selective electrodes, Anal. Chim. Acta 648 (2009) 240-245.

[40] J.W. Ding, W. Qin, Current-driven ion fluxes of polymeric membrane ionselective electrode for potentiometric biosensing, J. Am. Chem. Soc. 131 (2009) 14640-14641.

[41] J.W. Ding, W. Qin, Potentiometric sensing of nuclease activities and oxidative damage of single-stranded DNA using a polycation-sensitive membrane electrode, Biosens. Bioelectron. 47 (2013) 559-565.

[42] E. Bakker, E. Pretsch, P. Bühlmann, Selectivity of potentiometric ion sensors, Anal. Chem. 72 (2000) 1127-1133.

[43] E.M. Zahran, V. Gavalas, M. Valiente, L.G. Bachas, Can temperature be used to tune the selectivity of membrane ion-selective electrodes, Anal. Chem. 82 (2010) 3622-3628.

[44] K.Y. Chumbimuni-Torres, C. Thammakhet, M. Galik, P. Calvo-Marzal, J. Wu, E. Bakker, G. Flechsig, J. Wang, High-temperature potentiometry: modulated response of ion-selective electrodes during heat pulses, Anal. Chem. 81 (2009) 10290-10294.

[45] X. Gao, Y. Yang, C. Wang, Geochemistry of organic carbon and nitrogen in surface sediments of coastal Bohai Bay inferred from their ratios and stable isotopic signatures, Mar. Pollut. Bull. 64 (2012) 1148-1155.

[46] Y. Chen, G.P. Yang, G.W. Wu, X.C. Gao, Q.Y. Xia, Concentration and characterization of dissolved organic matter in the surface microlayer and subsurface water of the Bohai Sea, China, Continent. Shelf Res. 52 (2013) 97-107. 